\title{
Livelisystems: a conceptual framework integrating social, ecosystem, development, and evolutionary theory
}

\author{
Andrew R. Dorward ${ }^{1}$
}

\begin{abstract}
Human activity poses multiple environmental challenges for ecosystems that have intrinsic value and also support that activity. Our ability to address these challenges is constrained by, among other things, weaknesses in cross-disciplinary understandings of interactive processes of change in social-ecological systems. This paper draws on complementary insights from social and biological sciences to propose a "livelisystems" framework of multiscale, dynamic change across social and biological systems. This describes how material, informational, and relational assets, asset services, and asset pathways interact in systems with embedded and emergent properties undergoing a variety of structural transformations. Related characteristics of "higher" (notably human) livelisystems and change processes are identified as the greater relative importance of (a) informational, relational, and extrinsic (as opposed to material and intrinsic) assets, (b) teleological (as opposed to natural) selection, and (c) innovational (as opposed to mutational) change. The framework provides valuable insights into social and environmental challenges posed by global and local change, globalization, poverty, modernization, and growth in the anthropocene. Its potential for improving interdisciplinary and multiscale understanding is discussed, notably by examination of human adaptation to biodiversity and ecosystem service change following the spread of Lantana camera in the Western Ghats, India.
\end{abstract}

Key Words: environmental change; livelisystems; social-ecological systems

\section{INTRODUCTION}

The multiple environmental challenges that human activity poses for the planet's ability to support the adoption of highconsumption lifestyles by increasing numbers of people are well known: widespread overexploitation and pollution of natural systems is causing degradation and loss of local and global ecosystems and natural resource stocks and hence loss of ecosystem services on which human activities are critically dependent (Millennium Ecosystem Assessment 2005, Rockström et al. 2009, Foresight 2011, Raworth 2012). These problems, or rather the social-ecological systems (SES) with which they are concerned, have multiple characteristics that make them particularly difficult to understand and address: they are crossor multiscale, multidisciplinary, dynamic (with multidimensional structural changes and transformations), subject to behavioral uncertainty, involve nonlinear relationships and hence thresholds or tipping points, and have emergent and embedded properties (Gallopin 1991, Holling et al. 1998, Ostrom 2007, Perrings 2007 , Rammel et al. 2007, Anand et al. 2010, Rounsevell et al. 2010, An 2012, Schlüter et al. 2012).

Addressing these problems needs (1) better analytical and management processes for diagnosis of problems and development and implementation of solutions and (2) better understandings of fundamental SES processes as they respond to different stimuli. Better cross- disciplinary integration of theory, language, and information is a key challenge in this (Millennium Ecosystem Assessment 2005, Norgaard 2008, Ostrom 2009, Waring and Richerson 2011, Milner-Gulland 2012).

This paper draws on complementary insights from social and biological sciences to propose the foundations for a unifying conceptual framework of dynamic change across social and biological systems. After this introduction, the paper is structured in four parts. It begins with a review of existing frameworks to assess the strengths and weaknesses of these frameworks and gaps in the overall suite of SES frameworks in use. This leads on to the description of a "livelisystems" framework and then consideration of potential applications of the framework. The paper concludes with a brief discussion of strengths and weaknesses of the framework and ways in which it could be taken forward.

\section{EXISTING SOCIAL-ECOLOGICAL SYSTEMS FRAMEWORKS}

A range of different cross-disciplinary frameworks and models have been developed and applied for diagnosing problems and developing and implementing solutions in SES. In this section, we review a range of different approaches used in these frameworks and models. We start from simpler frameworks but note that, although these are accessible and useful in drawing attention to interactions between social and ecological or biophysical variables and processes, they find it difficult to give sufficiently symmetrical consideration to these interactions. We argue that more fundamental theoretical integration across social and biophysical processes is required and discuss alternative approaches to this.

We begin by recognizing that the terms "framework," "model," and "theory" are used (and indeed combined-for example, theoretical model or theoretical framework) in different ways. Following Ostrom (2009) and McGinnis (2011), we consider "frameworks" to identify categories and sets of variables relevant for study, with limited specification of the nature of relationships between them, wheras "theories" set out and evaluate general causal relationships between categories and sets of variables. "Models" specify these relationships in particular circumstances. Choices of theories, models, and frameworks in any analysis are determined by context, by the purposes of analysis, and by analysts' disciplinary interests (Schlüter et al. 2012). 
The first framework we consider, the EcoSystem Services (ESS) framework, has gained wide and enduring traction. Building on early work by Costanza and Daly (1992) and Perrings et al. (1992), the Millennium Ecosystem Assessment (MEA; 2005) set out a formal ESS framework to demonstrate the importance of ecosystems and ecosystems threats. It has been criticized for its limited conceptualization of ecosystems primarily as stock-flow systems, its application to partial rather than general equilibrium analysis, and its facilitation of the commoditization of ecosystem services (Gómez-Baggethun et al. 2010, Norgaard 2010). It also has limited theoretical content with regard to socioeconomic influences on and responses to change. It has, however, been widely used, both for conceptualizing human drivers and ecosystem stocks and flows, and in guiding research identifying and valuing first flows of ecosystem benefits and then the stocks they are derived from.

A framework whose terminology relates closely to the ESS framework (with "drivers" and "pressures" equivalent to the ESS "indirect" and "direct" drivers (Fisher et al. 2012)), is the DriversPressures-State-Impact-Response (DPSIR), which has been further developed into the Framework for Ecosystem Service Provision (FESP) (Rounsevell et al. 2010). Although similar to the ESS framework, the DPSR and FESP frameworks place more emphasis on the possibility of adaptation by ecosystem service providers (ecosystem elements or communities providing specific services) and, in the case of FESP, on responses by ecosystem beneficiaries. However such feedbacks are also allowed for in research frameworks that explicitly seek to operationalize the MEA, for example Taylor (2007).

An earlier social science-oriented framework with little emphasis on ecological elements was the "sustainable livelihoods approach" (Chambers and Conway 1992, Carney 1998). This was originally a checklist of issues to consider in analyzing sustainable rural livelihood constraints, opportunities, and interventions. As an analytical or development aid, it has value but is subject to criticism that even on socioeconomic issues it omits key issues, such as markets, institutions, and politics (Dorward et al. 2003) and lacks theory regarding processes and pathways of change and detailed links across different scales (Scoones 2009). It also lacks any specification of links across the natural and social sciences.

These frameworks are useful in setting out checklists of the elements of SES that need to be considered. Their weaknesses arise from (a) the elements that they omit and (b) the limits or lack of system behavior theories underpinning them. A key weakness is that, although both social and ecological elements may be included in the framework, we seldom find both social and ecological theory underpinning them (a possible exception is the application of the ESS framework to design schemes for payments for ecosystem services - although this raises fundamental objections about (a) the inadequacy of considering social relationships only through market exchanges and (b) about insufficient consideration of possible indirect effects and feedbacks (see, for example, McAfee and Shapiro 2010, Norgaard 2010, Maestre André et al. 2012, Muradian and Rival 2012).

Frameworks drawn from both social and ecological theory are more difficult to develop. Ostrom and others have developed a valuable framework for identifying and organizing relevant variables that affect self-organization by resource users in SESs
(Anderies et al. 2004, Ostrom 2005, 2007, 2009). These variables describe features of resource units, resource users, and resource and governance systems (the core subsystems for analysis of SESs), and these are brought together to allow integration of knowledge from biophysical and social science studies for use in data collection, fieldwork, and analysis of SES sustainability. Anderies et al. (2004) noted in early work with this framework that the original design principles did not explicitly address ecological dynamics: attention was needed to address "mechanisms related to the match between the spatial and temporal dynamics of ecological and social systems."

This match, perhaps the core problem in cross-disciplinary integration in SES, is the subject of a review of the implications of work on the interactions between human behavior and ecological systems for predictive systems ecology (MilnerGulland 2012). This reports considerable work examining oneway impacts - of humans on ecosystems or of ecosystems on humans - but much less examination of dynamic two-way interactions. Where such work has been done, it has been very valuable in showing the important effects of these interactions (e.g., Holdo et al. 2010) but tends to involve detailed systemspecific modeling rather than general theory, although agentbased modeling can provide a common tool and methodological framework. It is interesting that, coming at the problem from more of a conservation perspective, Milner-Gulland reaches symmetrical conclusions to those of Anderies et al. (2004), observing that "indirect effects of conservation interventions on biodiversity, modulated through human decision-making, are poorly studied" and calling for "an inter-disciplinary approach ... to quantify these interactions, with an understanding of human decision-making at its core." Janssen et al. (2006) and Bodin and Tengö (2012) raise similar concerns about SES frameworks' difficulties with coherent integration of social and natural sciences and with their representation of structural change. They advocate network theory and analysis as an approach that can address these difficulties in some situations. Like agent-based modeling, this is applied in both social and ecological science and provides common analytical concepts and tools. Social and natural scientists engaged in cross-disciplinary work on SESs therefore recognize the need for integration of "dynamics of ecological and social systems" but have had limited success and have limited tools to achieve this. Ideally, attempts to "bolt together" disciplinary understandings and methods around common methodological approaches and tools would be complemented by more fundamental integration of metatheoretical understanding. This requires a move from "mutual identification and cooperation" to "fundamental transformation" in such work (MacMynowski 2007) and from interdisciplinary to transdisciplinary modes of work with “epistemological pluralism” (MacMynowski 2007).

A core explanation for difficulties with SES frameworks and theory is likely to be the way that different disciplines operate with different conceptual frameworks regarding basic processes of change (Gintis 2007, Hodgson and Knudsen 2010a). This is undesirable in three ways. First, different disciplines may not only have different concerns and perspectives (which is valuable), but also incompatible models (Gintis 2007), with analysis of different variables and processes leading to incompatible analyses and difficulties in mutual comprehension. Second, if a 
framework in one discipline has great analytical power in another discipline, then failure to use the framework within the second discipline misses opportunities for expanding analytical insights in that discipline (as Hodgson and Knudsen (2010a) argue regarding the adoption of generalized Darwinism in the social sciences). Third, drawing on the first two points, work across disciplines becomes significantly more challenging if they do not share a common metatheoretical framework to unite and interface their different work and perspectives on different topics (Hodgson and Knudsen 2010a). To address these challenges, Mollinga (2010) calls for three types of "boundary work": the development of boundary concepts (cross-disciplinary terminology and multidimensional thinking), tools (analytical models and assessment frameworks), and settings (institutional arrangements for interdisciplinary work). The first need is echoed by Schlüter et al. (2012), who recognize considerable achievements in SES modeling but note "the need for a common analytical framework for SES" (Schlüter et al. 2012: 251).

Interest in evolution has been a dominant theme in work on the development of such metatheoretical frameworks. Hodgson has been a strong proponent for the adoption of "generalized Darwinism" as a uniting metatheoretical framework (e.g., Hodgson and Knudsen 2010a). Hodgson and coauthors develop this in substantial depth and detail. Gintis (2007) proposes "evolutionary theory," covering both genetic and cultural evolution, as the integrating principle of behavioral science. Norgaard has proposed "coevolutionary" theory as a way of linking analysis of social and ecological change, initially as "an appeal for theoretical pluralism" (Norgaard 1984) but more recently as a framework for explanation of sociocultural evolution in social sciences and for linking this to the biological sciences (Gual and Norgaard 2010). Although this has faced a number of criticisms, many of these arise because evolutionary concepts are being lifted out of a narrower biological context (concerned with biological processes, mechanisms, and variables) to fit in a wider context (concerned with social processes, mechanisms, and variables) without distinguishing, for example, between codynamics and Darwinian coevolution (Winder et al. 2005, Kallis 2007). Coevolutionary theory is also proposed for the conceptualization and understanding of uncertainty inherent in economic development processes, involving the coevolution of technical and institutional change (Nelson 2011). Rammel et al. (2007) explicitly draw on ideas from complex adaptive systems theory, evolutionary theory, and evolutionary economics to develop a coevolutionary perspective on natural resource management.

Waring and Richerson (2011) argue that Norgaard's framework could provide a basis for a unified framework for SES analysis and propose that, with the addition of three traditions of mathematical theory (the Lotka-Volterra interactions of ecological theory, niche construction models of population genetics, and gene-culture coevolution theory), this could form the basis for an operational "theory of social-ecological coevolution" with coupled models of environmental change and human behavior. Gene-culture coevolution also features in Gintis' unifying theory (Gintis 2007), whereas Laland and Boogert (2010) propose niche construction-both gene-based and cultural - as a dominant process in SES dynamics. Niche construction also provides the basis for the "extended evolutionary theory" proposed by Odling-Smee et al. (2003), wheras Jablonka and Lamb (2005) put forward a related but different "extended evolutionary theory" in their exposition of "evolution in four dimensions" (genetic, epigenetic, behavioral, and symbolic dimensions of variation, selection, and inheritance).

Other metatheoretical frameworks approach SESs in very different ways. Living systems theory, developed by Miller (Miller 1978, Miller and Miller 1992), adopts a systems approach in a formal description of hierarchical arrangements of nested and integrated biological and social systems arranged, from singlecelled organisms to supranational social systems, with formal functional sets of critical subsystems. Living systems theory has had limited application to SESs. Panarchy, another metatheoretical framework, focuses on linked, hierarchically arranged adaptive cycles representing cross-scale dynamic interactions and the interplay between change and persistence in a system (Holling et al. 2002).

Although these frameworks provide ways of conceptualizing the spatial and temporal dynamics of ecological and social systems, Gintis (2007) and Waring and Richerson (2011) also include methodological approaches or tools in the operational proposals for their frameworks - respectively, the use of evolutionary game theory and the coupling of specific mathematical modeling approaches. As discussed earlier, network theory and agent-based models provide two other methodological approaches to conceptualizing and modeling agents in social and ecological systems (Hird 2010, Rounsevell et al. 2012). Modeling of adaptive cycles has both theoretical and methodological significance in panarchy and potential for wider application (Widlok et al. 2012) and for links to agent-based modeling.

Coupled Human and Natural Systems or CHANS (Liu et al. 2007) has been developed as an approach with both theoretical and methodological elements that "aims to reveal the underlying rules and emergent properties of (SES), and the patterns and processes that link human and natural systems," emphasizing "the potentially unpredictable effects of humans, their organizations and practices on the environment, as well as the effects of environmental changes on human populations, institutions, and behaviors" and promoting "the integration of agency and multiscale interaction multiple organizational, spatial and temporal scales" (Hummel et al. 2012). However, Hummel et al. (2012) argue that CHANS needs to develop general principles, which themselves would need a "comprehensive theoretical framework" integrating different natural and social science perspectives.

Our review of different cross-disciplinary frameworks for understanding and modeling SES therefore leads from simpler interdisciplinary approaches with "mutual identification and cooperation" to the need for transdisciplinarity with a "fundamental transformation" involving "epistemological pluralism" (MacMynowski 2007). Evolutionary and coevolutionary theories are suggested by a number of authors as providing a possible basis for such an epistemologically pluralist transdisciplinarity. These then need to be integrated with multiscale systems theories and approaches.

Consideration of these frameworks and of the characteristics of SES (detailed earlier) suggests that a truly transdisciplinary and valid theoretical framework should have the following characteristics: 
Fig. 1. Livelisystems: broad processes and elements.

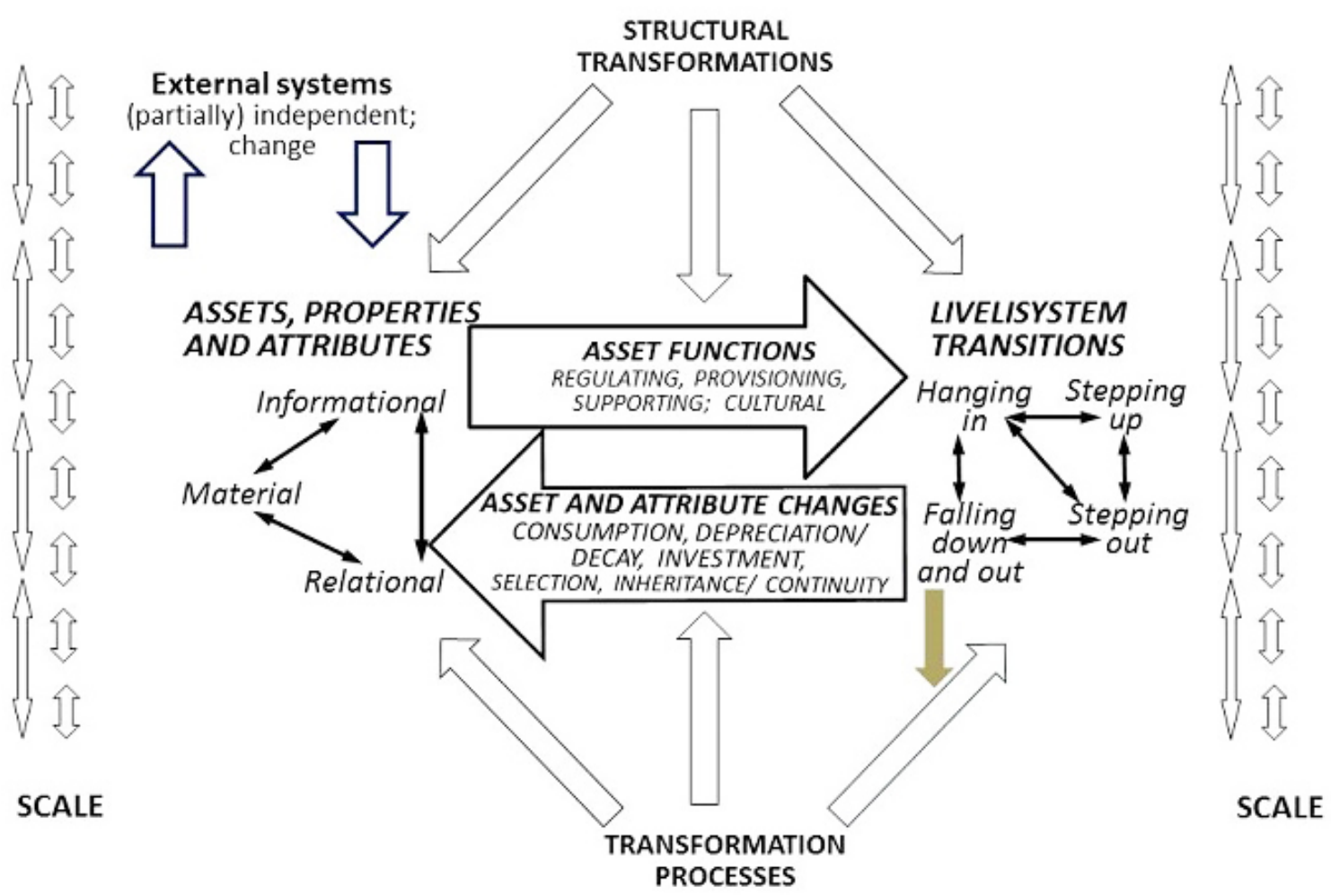

- It must be able to represent the characteristics of complex, coupled systems, describing multiscale, dynamic interactions between and within partially decomposable subsystems, allowing for emergent and embedded properties, various types of structural change and transformations, uncertainty, nonlinear relationships, and thresholds or tipping points;

- It should draw on and develop "boundary" insights, concepts, and language from a range of social and natural science disciplines;

- It should not be inherently anthropocentric or ecocentric, but should be capable of both anthropocentric and ecocentric application;

- It should be able to accommodate and mediate a variety of different disciplinary perspectives and investigational approaches and add to, rather than replace, the toolkit of approaches that analysts with different objectives need for studying SES with a variety of characteristics and contexts;

- Ideally, it should make separate contributions to the social and biological sciences apart from aiding their integration in the analysis of SESs; and
- It should stimulate innovative and valid conceptual and researchable questions and investigation as well direct researchers and practitioners toward key interventions and intervention points in SESs.

\section{A LIVELISYSTEMS FRAMEWORK}

To complement existing frameworks discussed above and in pursuit of a general conceptual framework with the characteristics put forward above, this paper postulates a framework that sets out elements and processes that constitute a "livelisystem," defined as:

\begin{abstract}
a combination of the functions provided by assets (or resources) and activities undertaken in and by open, structured, and actively self-regulating systems in maintaining negentropy (negative entropy) andlor increasing it with informational, material, and relational mechanisms for maintenance, growth, or multiplication.
\end{abstract}

This draws on conceptualizations of livelihoods (Chambers and Conway 1992), living systems (Miller 1978), and generative replication in complex population systems (Hodgson and Knudsen $2010 b$ ). It focuses attention in social or ecological system analysis on (a) functions of resources or assets (Kent and Dorward 2012b), (b) activities, (c) processes maintaining or increasing system order and negentropy, and (d) relationships of open systems with external systems. The broad processes and elements of a framework representing these features are set out diagramatically in Fig. 1.

This represents the processes maintaining or increasing system order and negentropy as "livelisystem transitions" (on the right), 
and links these to resources (on the left) termed "assets, properties, and attributes," which in turn are affected by and may or may not affect external systems (in the upper left of the figure). A distinction is made between asset properties (their essential and potential features) and asset attributes (the expression of an asset's properties in a particular ecological and social context) to allow for attributes (and hence the valuation of asset properties) varying in different ecological and socioeconomic contexts even if their properties do not vary. Assets by their attributes perform functions that affect livelisystem transitions and they are themselves affected by these transitions. These processes operate at different scales, with lower-level systems operating within higher-level systems and affected by other lower-level livelisytems within the same higher-level systems. However, they are also components of and therefore affect higher-level hierachies, with "sub-livelisystems" often acting as assets within a higher-level livelisystem. These cross-scale interactions are indicated by the vertical arrows on the sides of Fig. 1. Finally, livelisystem transitions and assets and attributes and the relationships between them are arranged in structures that may be transformed by a variety of processes.

We develop this conceptualization further by detailing categories of livelisystem transitions, asset functions, asset changes, assets and attributes, and flows between livelisystems and external systems.

First, building on Dorward et al. (2009a), four possible livelisystem transitions are defined: hanging in (maintaining the status quo), stepping up (increasing levels of existing sets or subsets of activities and/or assets and asset functions), stepping out (engaging in new activities with different assets and asset functions), and falling down and out (failing to maintain the status quo and falling to a livelisystem with lower attainment of sets or subsets of activities and/or assets and asset functions, possibly failing to maintain the livelisystem and survive). As noted earlier, these livelisystem transitions draw on asset functions and cause asset changes. The concept of asset functions is discussed more fully in Kent and Dorward (2012b). It is related to and includes ecosystem services, which, following Wallace (2007), Boyd and Banzhaf (2007), Jax (2010), and Kent and Dorward (2012b) are defined as "those services (or goods and services) which are provided by ecosystems and directly valued and consumed" by people. Ecosystem services are then a subset of ecosystem functions, defined by Kent and Dorward (2012b) as "the primary, intermediate and final (ecosystem) processes which support and deliver goods and services.” As with Jax's (2010) consideration of ecosystem processes, this avoids difficulties in distinguishing between intermediate and final services.

Following the MEA, we then categorize these functions as regulating, provisioning, supporting, and cultural (MEA 2005): this is a helpful classification of functions performed by all forms of capital,e.g., physical, social, and human as well as natural capital (Waage et al. 2010). Asset functions can be further classified into more detailed categories: Dorward et al. (2005), for example, apply the concept to analysis of livestock roles in poor people's livelihoods in Mexico and Bolivia and categorize these in terms of production, consumption, accumulation, buffering, insurance, protecting, and social integration functions. Kent and Dorward (2012b) add to this "transformative functions," which involve different kinds of physical transformations: livestock, for example, may transform dispersed, low nutritional quality forage in one season to make this available as concentrated high quality human food at a later season. This involves spatial, qualitative, and temporal transformations.

Livelisystem transitions affect asset properties and attributes in a variety of ways. Asset and attribute depletion (including loss of properties needed for particular functions) may occur where asset stocks are directly consumed, destroyed, decay, or "depreciate" at a faster rate than they are generated or renewed (within or outside the livelisystem) or where processes (e.g., waste generation) undermine them. There may also be accumulation where "investment" or other positive effects lead to faster generation and renewal than depletion. Processes of asset and attribute gain or loss may involve positive or negative feedbacks with livelisystem transitions and may lead to differential selection of assets and attributes, and with the information transfer mechanisms for replication or reproduction inherent in our definition of livelisystems, this leads to inheritance ("the passing of information concerning adaptive solutions from one entity to another" (Hodgson and Knudsen 2010a: 239). Selection and inheritance constitute two of the three necessary processes of Darwinian evolution, the third being variation, which may result from endogenous change processes, which we discuss later.

Assets are composed of material, informational, and relational resource types. Informational and material resources coincide with the two core elements identified in Miller's living systems theory, information and matter-energy (Miller 1978) and with the conceptualization of informatic and physical (energy and material) resource components in ecological inheritance systems (Odling-Smee 2007, 2010). Relational elements describe claims and obligations that systems or subsystems have on or to other systems or subsystems. The three resource types are structurally related to each other in that relational resources are normally embedded in some form of informational resource, and informational resources in some form of material resource.

The "material, informational, and relational" categorization of assets can be applied in two ways. First, with regard to asset composition, assets are made up of material, informational, and relational elements. Second, the categorization also applies in describing the mode of operation of the asset: do an asset's functions involve material, informational, and/or relational contributions to a livelisystem? Assets may also be classified in other ways: for example, it may be helpful to categorize assets as natural, physical, social, and human capital in some situations.

No categorization of asset attributes is shown in Fig. 1 for reasons of space. It should, however, be clear that differences in asset properties and their expression in different contexts mean that their contributions to different services, and hence their attributes, will also vary between contexts.

Drawing on and adding to livestock attributes identified by Dorward et al. (2005), a list of attributes is set out in Table 1 as an illustrative starting point. Different functions and attributes may have more or less relevance to different social and ecological processes and analysis (and many assets will be "sublivelisystems" with their own emergent, embedded, and nonlinear properties). Their specification will thus vary substantially between different 
Table 1. Asset attributes

\begin{tabular}{|c|c|c|}
\hline Main Attribute & $\begin{array}{l}\text { Contributing to which function } \\
\text { (s) }\end{array}$ & Components \\
\hline Productivity & Production, income & $\begin{array}{l}\text { Productivity (or throughput) under expected, average or "normal" } \\
\text { conditions; variability; sensitivity to and resilience under different } \\
\text { conditions; probability of these different conditions occurring; appreciation } \\
\text { of asset value }\end{array}$ \\
\hline Utility & Income, consumption & $\begin{array}{l}\text { "Normal" utility or wellbeing; variability; sensitivity to and resilience under } \\
\text { different conditions; probability of these different conditions occurring }\end{array}$ \\
\hline Security & All, especially saving & $\begin{array}{l}\text { Risk of theft or of loss of control or access; susceptibility to pathogens or } \\
\text { other "natural" event. For debts: risks to collateral or collateral substitutes }\end{array}$ \\
\hline Holding costs & Detracts from all & $\begin{array}{l}\text { Maintenance and input costs (including time, claims, etc.) borne by different } \\
\text { stakeholders and depreciation in time and in use under normal conditions; } \\
\text { variability under different conditions; probability of different conditions }\end{array}$ \\
\hline Life & All & $\begin{array}{l}\text { Expected period over which asset will be held under normal conditions; } \\
\text { variability under different conditions; probability of different conditions. } \\
\text { Asset value profile (seasonal, lifecycle changes) }\end{array}$ \\
\hline Depreciation & All & $\begin{array}{l}\text { Rate of loss of function / service, affected by use, investment, environment, } \\
\text { etc. }\end{array}$ \\
\hline Convertibility & $\begin{array}{l}\text { Sales income, savings, } \\
\text { buffering, insurance }\end{array}$ & $\begin{array}{l}\text { Exchange costs and access under normal conditions; variability under } \\
\text { different conditions; probability of different conditions. Lumpiness: related } \\
\text { to unit value of sale and ease of sale }\end{array}$ \\
\hline Complementarity & Production, income & Effects on and of other assets and their functions \\
\hline Ownership/control & All & $\begin{array}{l}\text { Private (individual, household); communal; public; gendered rights and } \\
\text { responsibilities for disposal, acquisition, costs, and returns }\end{array}$ \\
\hline Divisibility & All & $\begin{array}{l}\text { Minimum functional scale (may vary across services), variation of other } \\
\text { attributes with scale }\end{array}$ \\
\hline $\begin{array}{l}\text { Dispersion/ } \\
\text { concentration }\end{array}$ & All & Spatial and temporal distribution could also be applied to ownership \\
\hline
\end{tabular}

Adapted from (Dorward 2005 \#15; Alwang and Siegel 1999 \#98)

livelisystems and analyses and, depending on their essential properties, will be both contextually and socially defined (Kent and Dorward 2012b). The "second-tier system variables" identified by Ostrom (2007) and others in their framework for analyzing SES provide further options for specifying and categorizing asset attributes.

Two further dimensions of assets and attributes should also be recognized. The first, regarding processes of change, recognizes that assets and attributes are subject to endogenous changes as well as changes effected by external systems and by livelihood transitions (as described earlier). Endogenous changes may arise as a result of mutation, innovation, and/or recombination (where mutation describes random changes generally arising in processes of replication, innovation describes intentional changes, and recombination describes new combinations of core characteristics, composition, and structure of assets and their attributes). Mutation and innovation may act in combination or singly, and may affect material, informational, or relational elements of assets. These endogenous change mechanisms are critical in promoting variation, the third of the three necessary processes of Darwinian evolution mentioned earlier.

The second dimension of assets that we consider in livelisystems analysis distinguishes between assets that are intrinsic or extrinsic to entities in a livelisystem (or integral or not integral parts of those entities). Examples of extrinsic assets might include animals' nests and burrows, machinery, information technology systems, and relational assets.

Consideration of extrinsic and relational assets raises questions about livelisystem boundaries and relationships with external systems. Defining boundaries of open systems requires problem and context-specific determination. Feedbacks between systems depend upon the extent of coupling and the relative scales and numbers of interacting systems - hence their partial independence. It is helpful, however, to recognize different categories of change in external systems (e.g., "normal" apparently random variation, shocks, cycles, and trends) as these will have different impacts on livelisystems, and to recognize different types of flows between livelisystems and their environment, with material, informational, and relational resources and waste flowing in and out, and a maintenance of negentropy by taking in resources with lower entropy than the "waste" they emit or expel.

Many of the categorizations discussed above (but for simplicity of presentation not shown in Fig. 1) will often not be rigid, tightly defined, or separate and mutually exclusive. The boundaries between categories and different categorizations will instead often be fuzzy and overlapping, both within and across hierarchies of 
scale. Thus, the four categories of livelisystem transitions (hanging in, stepping up, stepping out, and falling down and out) may be present together, and particular processes (take, e.g., a switch from less to more intensive cropping systems in an socialagro-ecological system or a species transition from crawling to running) might be seen as stepping up (of agricultural productivity or mobility, respectively) or stepping out (from one crop to another or from one form of locomotion to another). Similarly, asset services might be categorized differently in different types of analysis or at different scales of analysis (for example a service categorized as "supporting" at a higher scale of analysis might be considered a "provisioning" service at a lower scale of analysis). This is one way of addressing difficulties in defining and distinguishing between direct and indirect services and functions in the ecosystem services framework (Jax 2010).

We conclude our introduction to the livelisystems framework by noting the variety of processes and system characteristics that may be examined by cross-scale contextualized analysis of livelisystem transitions and their interactions with evolving assets and attributes. These include critical ecological, social, and SES features such as embeddedness, emergence, coevolution, coordination, complexity, stochasticity, thresholds and tipping points, irreversibility, and path dependence. Similarly, a wide range of different types and dimensions of structural transformations may be considered, such as spatial, temporal, or sectoral changes; physical, ecological, or biological changes; or institutional, political, economic, or trophic changes. These may be associated with a wide range of transformation processes, e.g., of accumulation, differentiation, specialization, substitution, diversification, or adaptation. These may then be considered at and applied to different, and multiple, scales of analysis - from genes to the biosphere or from individuals to much larger societies.

\section{APPLICATION AND DISCUSSION}

The conceptual framework set out in the previous section can be applied in a number of ways. Paradoxically, its metatheoretical nature means that specific applications of the whole framework will be relatively rare: in providing a framework for bringing together understandings, analysis, and investigations across SES, it allows a holistic but more general integration of different parts, as called for by Schlüer et al. (2012). This, and the wide range of contexts in which it may be applied, makes it difficult to evaluate the practical and applied strengths of such a framework until there have been a number of different attempts to use it. Therefore, this section discusses some preliminary observations on three widely differing types of application, first regarding initial general conceptualization of SES research problems, second in investigating local effects of and responses to exogenous (in this case, biodiversity) change, and third in initial conceptualization of complex multiscale changes and interactions within and across a much larger system and set of subsystems.

Limited experience in broader use of the framework suggests that it can provide a valuable starting point for investigation of particular parts of livelisystems by defining core research questions within an integrating structure (du Toit, pers. comm., e.g., reports that research students to whom he introduced it "were usually interested in only one part or another of the framework, but that the framework as a whole served as a useful way of being able to show where they were, and how the problematic they were interested in related to those of others"). These core research questions could, for example, iteratively examine where livelisystem boundaries can be drawn, the main hierarchical and overlapping components, what resources and attributes provide what services, what livelisystem transitions are occurring, what options or possibilities there are for different livelisystem transitions, how asset attributes and livelisystem transitions are mediated by their location in the system, the vulnerability and resilience of livelisystems and of different elements in livelisystems and the causes of their vulnerability, what structural transformations and processes are unfolding and their drivers and feedback effects, and key relations with external systems and how may these be changing. Such questions have the potential for immediate relevance - in identifying, e.g., critical asset properties and attributes for particular functions, particular exogenous and endogenous threats to these, and hence the need for particular policy, behavioral, institutional, investment or other interventions to promote particular assets, attributes, functions or entities in a livelisystem. These questions have been posed in ways that are applicable to both natural and social systems and subsystems. More specific question topics that might be appropriate to social systems might concern institutional or knowledge change or power, whereas topics more appropriate to ecological systems might concern, e.g., trophic pathways or environmental change.

A specific example of the application of part of the framework at a fairly local scale is its use in investigating impacts of and responses to biodiversity change in the Western Ghats, India. This involved a fairly rapid study of the impacts of the invasive spread of Lantana camera and of human adaptation to this in a village in the Male Mahadeshwara Hills Forest Reserve, southern Karnataka. In this village, occupied by people from two different ethnic groups, Lingayats and Soligas, the spread of Lantana has caused a decline in availability of forest products (including grazing for cattle), obstruction of movement of humans and animals in the forest, and increased risk of encounters with wild animals (see Kent and Dorward (2012a,b) for a fuller description).

Before engaging in fieldwork, the multidisciplinary research team used the livelisystems framework to develop a specific conceptual framework for investigating both the impacts of the spread of Lantana on people's livelihoods and people's responses to this The core elements and relationships between them were identified by drawing from the livelisystems framework particular elements that were perceived to be critically relevant to the problem being researched: human adaptation to biodiversity change caused by the spread of Lantana. These elements are presented in Fig. 2, although the final representation used by the team (Kent and Dorward 2012b) omitted explicit reference to elements in italics in Fig. 2 (an example of the eclectic use of specific parts of the framework to match specific contextual interests). Differences between the representation in Fig. 2 and that in Kent and Dorward (2012b) demonstrate the way the framework can be adapted to or within different disciplinary interests or perspectives.

The framework focuses on examination of the effects of Lantanainduced biodiversity change and other exogenous changes on asset properties, attributes, functions, and use and on people's livelihoods, with a particular emphasis placed on human adaptation and the shaping of decisions by knowledge and values. The focus on asset properties and attributes provided critical 
Fig. 2. Conceptual framework: human adaptation to biodiversity change.

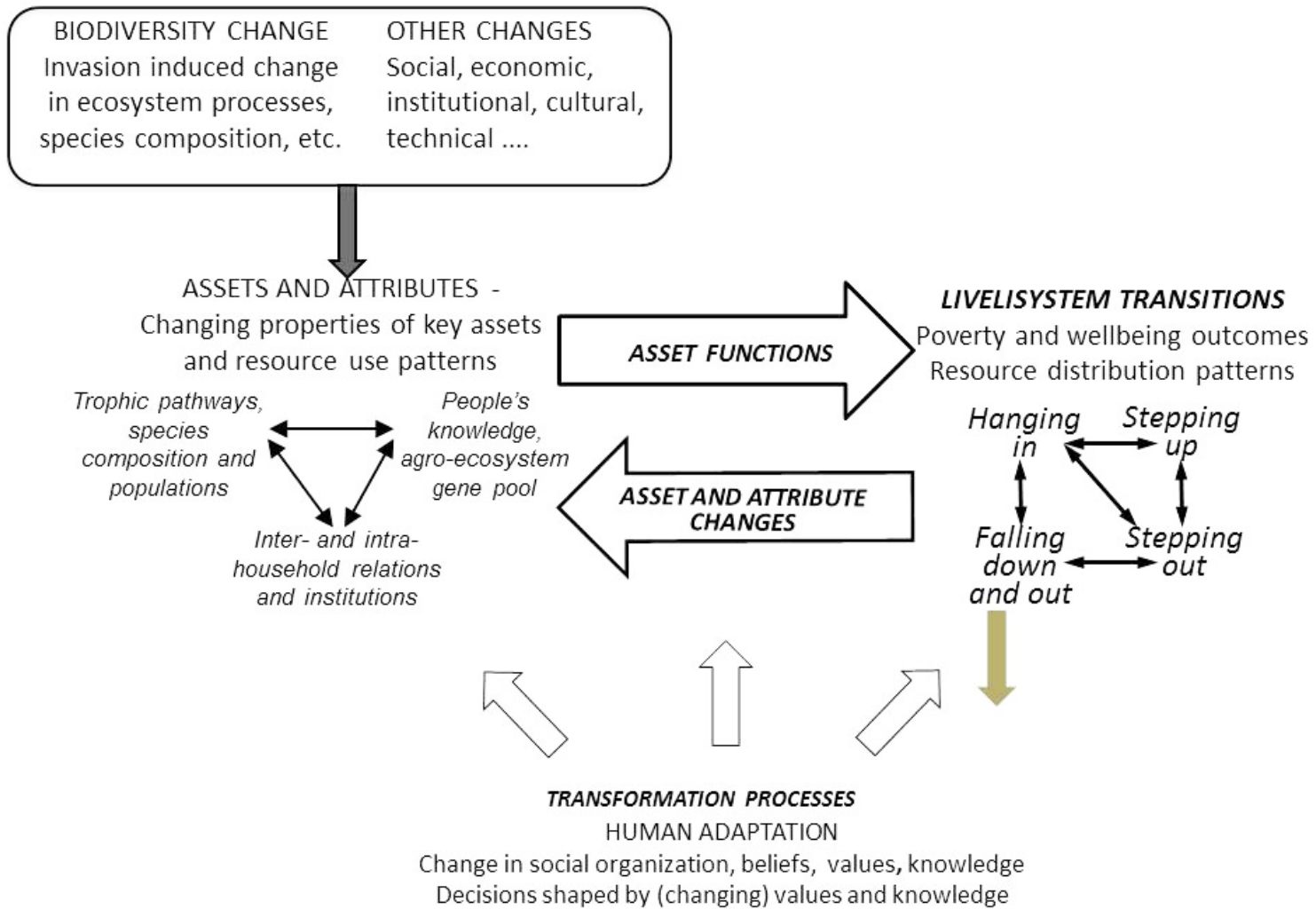

"boundary concepts" that both linked disciplines (ecology, anthropology, and economics) and allowed separate investigation of elements of specific disciplinary interest (as illustrated by the combination of ecological and social elements listed as examples of material and informational asset elements in Fig. 2). The framework also allowed development of common "boundary tools" linking researchers and local people: qualitative interviews considering the functions and attributes of forest assets for different groups of users and perceptions of how these had changed over time.

Table 2 provides a general, aggregate summary of assets and their functions in livelihoods, distinguishing between those managed and held by households or by the wider community. This locates the contributions of the forest to different asset functions as people draw on forest resources as part of diverse livelihood strategies that involve crop production, livestock raising, and extraction of forest products (for income and subsistence) alongside labor migration, use of savings, and credit services from self-help groups (SHG), and consumption of public distribution system (PDS) grain.

Because households have little power to control the spread and impact of Lantana, consideration of asset properties and differentiated attributes and functions allowed analysis of people's adaptation to changes in the forest by finding substitutes for the functions previously derived from the forest. The capacity for such adaptation varied considerably between households and individuals as a result of variations in access to nonforest assets. This variation was the focus of the next stage of analysis, beyond the broad summary presented in Table 2, and was most apparent with regard to households' ability to substitute forest-derived income with wages from migrant work. Here, extended households containing both adult sons (able to take turns to leave for migrant labor) and parents (able to maintain the farm and/or look after cattle) have adapted to the effects of the loss of forest grazing with increased periodic migrant labor and earnings. This has facilitated investments in house building and in agriculture by extended households, which are more common in the Lingayat community, whereas the more nuclear Soliga households tend to be in a more precarious position in adapting to loss of forest assets.

Differences between the Lingayat and Soliga communities were also found in the use of bamboo for basket making and in the collection of Phoenix or broom (an understory palm). Both activities provide a source of cash income and are potentially open to all, but the former is more prevalent among men in Soliga households and the latter more important for women in Lingayat households. Soliga mens' engagement with basket making appears to be related to its compatibility with migrant labor and to possibilities for accessing credit and consumption smoothing through advance payment from traders. Lingayat women, on the other hand, value the collection of broom as its compatibility with domestic tasks make it one of the few income-earning options 
Table 2. Household and community / local-level assets fulfilling asset functions

\begin{tabular}{|c|c|c|}
\hline Asset function categories & Household level & Community and local level \\
\hline Consumption & Grain stores; PDS ration; houses & $\begin{array}{l}\text { Forest products: foods (fruits, tubers, greens, } \\
\text { game); fuelwood; timber; bamboo; }\end{array}$ \\
\hline Social/ cultural functions & Livestock; houses; labor & Forest; temples/shrines; \\
\hline Productive/transformative functions & $\begin{array}{l}\text { Farmland; livestock; ploughs; labor; } \\
\text { houses }\end{array}$ & Forest; labor; school; \\
\hline Exchange functions & $\begin{array}{l}\text { Farm products (maize, ragi); labor; } \\
\text { livestock }\end{array}$ & $\begin{array}{l}\text { Forest products (broomstick, forest fruits, } \\
\text { bamboo, firewood). }\end{array}$ \\
\hline Savings functions & $\begin{array}{l}\text { Livestock; SHG savings; bank savings; } \\
\text { jewelry }\end{array}$ & \\
\hline Protective functions & $\begin{array}{l}\text { Livestock; bank savings; jewelry; } \\
\text { insurance; }\end{array}$ & $\begin{array}{l}\text { SHG credit; forest products; money lenders; } \\
\text { PDS }\end{array}$ \\
\hline Regulating functions & & Forest, other environmental assets \\
\hline Supporting functions & & $\begin{array}{l}\text { Forest, other environmental assets; health } \\
\text { services; water pump, roads, transport. }\end{array}$ \\
\hline
\end{tabular}

available to them. It also provides income for the regular savings required for membership of micro finance SHGs. Any Lantanainduced decline in access to or availability of bamboo and broom collection may then have differential impact on men and women and on Lingayat and Soliga households.

This case demonstrates the usefulness of a focus on assets (and their properties, functions and attributes) as "boundary concepts" for researchers from different disciplines, in setting asset attributes within a wider context of social and economic change (not explicitly discussed here), and in providing valuable insights into differential responses and vulnerabilities to biodiversity change in SES analysis. The findings suggest that policy responses and specific interventions supporting adaptation need to pay particular attention to understanding of and differential attention to different groups' portfolios of asset functions; to the attributes of these assets within particular social, institutional, economic and biophysical contexts; and to the ways these are affected by biodiversity and other changes.

An example of a more multiscale application of the framework is provided by early stages of work investigating interactions between population growth in Malawi, land-use change, changes in agricultural practices, changes in the ecology and productivity of Lake Malawi, and local and national food security in the context of ongoing climate change effects. Malawian agriculture is affected by soil deterioration and declining farm sizes, soil fertility, yields, and labor productivity, which have contributed to widespread rural poverty and food insecurity (Chirwa and Dorward 2013). Associated land-use changes have also increased runoff and erosion and hence sediment loads in rivers and in Lake Malawi, affecting its ecosystem and fisheries (Otu et al. 2011). Downstream effects in freshwater systems also interact with temperature changes in the lake (associated with climate change), causing significant changes in the lake's limnology (Vollmer et al. 2005) and fished shallow and deepwater fish communities (Otu et al. 2011). Fisheries in turn affect lakeshore livelihoods and the protein supply to upland communities. Widespread agricultural intensification can address some of these problems, but increased use of inorganic nitrogenous and phosphate fertilizers also carries risks of increasing nutrient loads in runoff and drainage water, again with negative downstream effects on freshwater systems.
Investigation of interacting processes and of policy, institutional, and technical options for addressing the negative trends affecting natural and social systems requires a transdisciplinary SES approach. Figure 3 sets out an initial conceptualization of the overall national/catchment livelisystem to define the broad scope and structure of the systems under study. It is presented at a high level of generality and abstraction, with some eclectic illustrative detail, to allow space for different specialists (e.g., socioeconomists, agronomists, soil scientists, limnologists, hydrologists, fisheries scientists, and fish ecologists) to develop their own multiscale disciplinary and contextualized frameworks while developing and sharing common boundary concepts in and for cross-disciplinary engagement.

Use of this conceptualization in the development and coordination of research will involve representations of the core social, economic, agronomic, ecological, and environmental relationships across multiple scales of analysis, and of different social, ecological, and social-ecological subsystems within these different scales. External in and out flows for each livelisystem will then be linked within and across the different scales, with the common framework allowing aggregation of lower-scale livelisystems into higher scales (together with components that are absent from lower scales), with explicit cross-sector and crossscale interlocking points. Within each livelisystem, analysis (and hence potential interventions) will focus on asset property, attribute and function changes, and on livelisystems transitions (e.g., soil properties, input use, land productivity, fish populations, and stepping up or out of agriculture and/or fishing into other activities) as these drive wider structural transformations (e.g., in agricultural, fisheries, and other sector balances, agriculture and forest land uses, Lake Malawi's trophic systems, demography, and institutions).

This broader case illustrates the way that the livelisystems conceptualization provides both boundary concepts and boundary objects to facilitate analytical work within and integration across different social, economic, agronomic, and ecological investigations and scales of analysis. The larger-scale and longer-term focus in this case also requires attention to technical and institutional change and hence endogenous (innovational, mutational, and recombination) change processes 
Fig. 3. Generic lake/catchment livelisystems framework, Malawi.

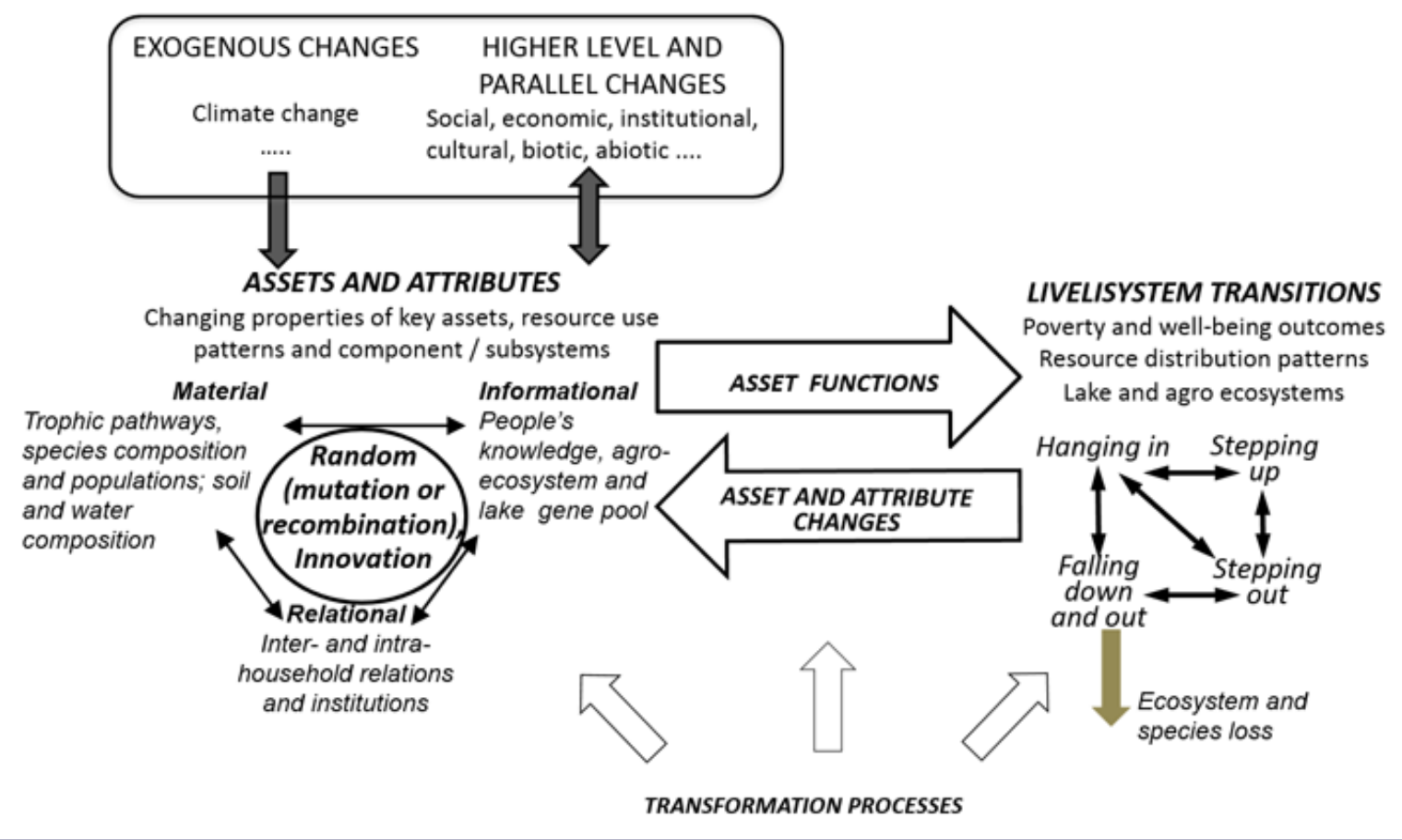

and the informational and relational composition, operation and evolution/ development of assets.

Beyond suggesting a general structured approach to investigation of specific biological and social systems as suggested in the cases above, the framework also raises questions about and provides insights on wider topics and processes. A major challenge faced in economic policy and practice, for example, is conceptualizing the multiscale and multidimensional dynamics of structural change. The framework's characterization of hanging in, stepping up, and stepping out transitions at multiple scales addresses this and highlights the need in socioeconomic policy for coordinated change in, for example, demand and supply across a range of complementary activities and services at different livelisystem scales (Dorward et al. 2009b). Core evolutionary processes involve similar multiscale, complementary, and interacting "coevolutionary" change across different genes, cells, organisms, species, and ecosystems. Social and biological evolutionary processes may be distinguished from each other by the greater importance of culture in social processes, but these interact in gene-culture evolution in human systems, whereas the importance of social learning and stable transgenerational culture in nonhuman species is increasingly recognized (Laland and Boogert 2010). There are also parallels and continuities with regard to changes in the relative importance of intrinsic and extrinsic assets and of material, informational, and relational capital, and of their interaction. These differences may be seen as key elements of socioeconomic development - e.g., it appears that systems within more developed societies tend to be characterized by greater reliance on extrinsic informational assets. It may, indeed, be possible to trace a global SES evolutionary pathway in terms of the interactions between and relative importance of extrinsic, informational, and relational assets. Alternatively, at a more micro level, the framework has the potential to take forward work on asset-based poverty and poverty measures (Carter and Barrett 2006, Liverpool-Tasie and Winter-Nelson 2011) through its emphasis on a wide set of assets, the different functions they perform, and their related and contextualized attributes.

The increasing importance of relational capital as systems develop suggests potential insights from cross-disciplinary investigation of the concept of "niche construction." Laland and Boogert (2010) note the importance of niche construction in human societies and their interactions with the natural environment. In the livelisystems framework, this raises questions about system boundaries between and definitions of relational assets and external systems, and about the role of power in defining boundaries and relationships (as well as in innovation and selection processes). Concepts of "roving and stationary bandits" may have widespread value and validity across their original application in political and economic development (Olson 1993) to natural resource management (Ostrom 2007) and wider predator-prey and parasitic relationships.

\section{CONCLUSIONS}

The desirable specifications set out earlier for a transdisciplinary and valid theoretical framework provide a benchmark against which the livelisystems framework may be evaluated - and the description of the framework and of its application suggests that it performs relatively well on these specifications.

- Its structure is explicitly multiscale and dynamic, with multiple components and subsystems that provide potential for emergent and embedded properties, for multiple 
structural transformations, and for a variety of disciplinary perspectives and investigational approaches.

- Its cross-disciplinary roots, concepts, and language (drawing on livelihood and other development studies and economics concepts, ecosystem service categorizations, and living systems, panarchy, niche construction, CHANS, and extended evolutionary theories) are an explicit strength that, with its system components, allows mediation and integration and hence complementarity with and between perspectives and investigational approaches from different disciplines and from the various frameworks reviewed earlier.

- It is neither inherently anthropocentric nor biocentric, but capable of application in both contexts.

- It provides a metatheoretical framework for contributions to individual disciplines and to stimulate conceptual development and research within disciplines and at their interface with other disciplines. Its cross-disciplinary roots and multiscale structure should make it methodologically flexible and inclusive, as subsystems can be defined and investigated in a variety of ways. In this, it complements and can provide a context for, rather than compete with, a number of the approaches and frameworks reviewed earlier.

- Finally, as the discussion of the two applications suggests, the framework may offer analysts and researchers opportunities for developing boundary concepts to aid work across disciplines, with eclectic use of relevant elements from the livelisystems conceptualization as an integrative context for use of existing SES analysis approaches and of more disciplinary-based analytical approaches within it. The focus on asset properties, functions, and attributes and their links to other elements in the framework (such as livelisystem transitions) also offer opportunities for the identification of specific interventions. These may, for example, identify critical asset functions and attributes for particular livelisystem transitions and potential means of supporting development of existing or substitute assets and/or external relationships that can replace them.

We conclude by suggesting two ways in which the framework can and should be taken forward - further conceptual development and wider application. First, there is a need for further conceptual development. Perhaps the most obvious weaknesses in the exposition in this paper are the need for a clearer conceptualization of relational assets (with specific regard to theories of niche construction, the definition of system boundaries, and conceptualizations of power, as touched on earlier) and the need for development of a more holistic set of asset attributes concerned with regulating, supporting, and cultural functions.

Conceptual advances on these and other topics will both benefit from and contribute to wider application of the framework. There is a wide range of systems where the concrete application of the framework could potentially improve both understanding and management of or responses to change. However, fuller appreciation of the framework's strengths and weaknesses needs its wider application and testing - by different teams with different interests and disciplinary expertise and approaches, and investigating different SES, at different scales, in different contexts, and facing different problems. These might include climate, food or agri-health systems (at local and wider, up to global scales); specific resource, conservation or ecosystems; and particular species in different contexts. There are also opportunities for more theoretical applications. As an example, these might investigate the hypothesis that more "advanced" evolution and development involve increasing relative importance of relational and extrinsic assets and of change through teleological selection and innovation. This hypothesis raises questions about the need for and nature of new "anthropocenic processes" of livelisystem evolution and development in an increasingly globally organized and environmentally challenged society.

Responses to this article can be read online at: http://www.ecologyandsociety.org/issues/responses. $\mathrm{php} / 6494$

\section{Acknowledgments:}

I am grateful to colleagues in the ESPA framework project "Human Adaptation to Biodiversity Change" for stimulating discussion of issues and to Harry Biggs, Andries du Toit, E. J. Milner Gulland, Jeff Waage, and anonymous reviewers for helpful comments on earlier drafts of this paper. Rebecca Kent did the field work and much of the thinking on the Western Ghats case study and made significant comments on earlier drafts of the paper. This work was partly funded under framework grant "Human Adaptation to Biodiversity Change" (PFG NE/1004149/1), with support from the Ecosystem Services for Poverty Alleviation Programme (ESPA). The ESPA programme is funded by the Department for International Development (DFID), the Economic and Social Research Council (ESRC) and the Natural Environment Research Council (NERC). The views and any errors or omissions are the author's sole responsibility and do not represent those of any other parties.

\section{LITERATURE CITED}

Alwang, J., and P. B. Siegel. 1999. An asset-based approach to social risk management: a conceptual approach. Social Protection Discussion paper 9926. World Bank, Washington, D.C., USA.

An, L. 2012. Modeling human decisions in coupled human and natural systems: review of agent-based models. Ecological Modelling 229:25-36.

Anand, M., A. Gonzalez, F. Guichard, J. Kolasa, and L. Parrott. 2010. Ecological systems as complex systems: challenges for an emerging science. Diversity 2:395-410. http://dx.doi.org/10.3390/ d2030395

Anderies, J. M., M. A. Janssen, and E. Ostrom. 2004. A framework to analyze the robustness of social-ecological systems from an institutional perspective. Ecology and Society 9(1): 18. [online] URL: http://www.ecologyandsociety.org/vol9/iss1/art18/ 
Bodin, Ö., and M. Tengö. 2012. Disentangling intangible socialecological systems. Global Environmental Change 22:430-439.

Boyd, J., and S. Banzhaf. 2007. What are ecosystem services? The need for standardized environmental accounting units. Ecological Economics 63:616-626.

Carney, D., editor. 1998. Sustainable livelihoods: what contribution can we make? Department for International Development (DFID), London, UK.

Carter, M. R., and C. B. Barrett. 2006. The economics of poverty traps and persistent poverty: an asset-based approach. Journal of Development Studies 42:178-199. http://dx.doi.org/10.1080/002$\underline{20380500405261}$

Chambers, R., and G. R. Conway. 1992. Sustainable rural livelihoods: practical concepts for the 21st century. IDS Discussion Paper No 296. IDS, Brighton, UK.

Chirwa, E., and A. R. Dorward. 2013. Agricultural input subsidies: the recent Malawi experience. Oxford University Press, Oxford, UK. http://dx.doi.org/10.1093/acprof:oso/9780199683529.001.0001

Costanza, R., and H. Daly. 1992. Natural capital and sustainable development. Conservation Biology 6:37-46.

Dorward, A. R., S. Anderson, Y. Nava, J. Pattison, R. Paz, J. Rushton, and E. Sanchez Vera. 2005. A guide to indicators and methods for assessing the contribution of livestock keeping to livelihoods of the poor. Department of Agricultural Sciences, Imperial College, London, UK.

Dorward, A. R., S. Anderson, Y. Nava, J. Pattison, R. Paz, J. Rushton, and E. Sanchez Vera. 2009a. Hanging in, stepping up and stepping out : livelihood aspirations and strategies of the poor. Development in Practice 19:240-247.

Dorward, A. R., J. G. Kydd, C. D. Poulton, and D. Bezemer. 2009b. Coordination risk and cost impacts on economic development in poor rural areas. Journal of Development Studies 45:1093-1112.

Dorward, A. R., N. D. Poole, J. A. Morrison, J. G. Kydd, and I. Urey. 2003. Markets, institutions and technology: missing links in livelihoods analysis. Development Policy Review 21:319-332.

Fisher, J. A., G. Patenaude, P. Meir, A. Nightingale, M. Rounsevell, M. Williams, and I. H. Woodhouse. 2013. Strengthening conceptual foundations: analysing frameworks for ecosystem services and poverty alleviation research. Global Environmental Change 23:1098-1111.

Foresight. 2011. The future of food and farming: challenges and choices for global sustainability. Final project report, The Government Office for Science, London, UK.

Gallopin, G. 1991. Human dimensions of global change: linking the global and the local processes. International Social Science Journal 130:707-718.

Gintis, H. 2007. A framework for the unification of the behavioral sciences. Behavioral and Brain Sciences 30:1-16.

Gómez-Baggethun, E., R. De Groot, P. L. Lomas, and C. Montes. 2010. The history of ecosystem services in economic theory and practice: from early notions to markets and payment schemes. Ecological Economics 69:1209-1218.
Gual, M. A., and R. B. Norgaard. 2010. Bridging ecological and social systems coevolution: a review and proposal. Ecological Economics 69:707-717.

Hird, M. J. 2010. Coevolution, symbiosis and sociology. Ecological Economics 69:737-42.

Hodgson, G. M., and T. Knudsen. 2010a. Darwin's conjecture: the search for general principles of social and economic evolution. University of Chicago Press, London, UK.

Hodgson, G. M., and T. Knudsen. 2010b. Generative replication and the evolution of complexity. Journal of Economic Behavior and Organization 75:12-24.

Holdo, R. M., K. A. Galvin, E. Knapp, S. Polasky, R. Hilborn, and R. D. Holt. 2010. Responses to alternative rainfall regimes and antipoaching in a migratory system. Ecological Applications 20:381-397.

Holling, C. S., F. Berkes, and C. Folke. 1998. Science, sustainability, and resource management. Pages 63-102 in F. Berkes and C. Folke, editors. Linking social and ecological systems. Cambridge University Press, Cambridge, UK.

Holling, C. S., L. H. Gunderson, and G. D. Peterson 2002. Sustainability and panarchies. In L. H. Gunderson and C. S. Holling, editors. Panarchy: understanding transformations in human and natural systems. Island Press, Washington, D.C., USA.

Hummel, D., S. Adamo, A. De Sherbinin, L. Murphy, R. Aggarwal, L. Zulu, J. Liu, and K. Knight. 2013. Inter- and transdisciplinary approaches to population- environment research for sustainability aims: a review and appraisal. Population and Environment 34(4):481-509.

Jablonka, E., and M. J. Lamb. 2005. Evolution in four dimensions: genetic, epigenetic, behavioral, and symbolic variation in the history of life. MIT Press, Cambridge, Massachussetts, USA.

Janssen, M. A., Ö. Bodin, J. M. Anderies, T. Elmqvist, H. Ernstson, R. R. J. Mcallister, P. Olsson, and P. Ryan. 2006. Toward a network perspective on the resilience of social-ecological systems. Ecology and Society 11(1): 15. [online] URL: http://www. ecologyandsociety.org/vol11/iss1/art15/

Jax, K. 2010. Ecosystem functioning. Cambridge University Press, Cambridge, UK.

Kallis, G. 2007. When is it coevolution? Ecological Economics 62:1-6.

Kent, R., and A. Dorward. 2012a. Biodiversity change and livelihood responses: ecosystem asset functions in southern India. Working paper, Centre for Development, Environment and Policy. School of Oriental and African Studies (SOAS), University of London, London, UK.

Kent, R., and A. R. Dorward. 2012b. Conceptualising assets and asset services in livelihoods and ecosystem analyses: a framework for considering livelihood responses to biodiversity change. Working paper, Centre for Development, Environment and Policy. School of Oriental and African Studies (SOAS), University of London, London, UK.

Laland, K. N., and N. J. Boogert. 2010. Niche construction, coevolution and biodiversity. Ecological Economics 69:731-736. 
Liu, J., T. Dietz, S. R. Carpenter, C. Folke, M. Alberti, C. L. Redman, S. H. Schneider, E. Ostrom, A. N. Pell, J. Lubchenco, W. W. Taylor, Z. Ouyang, P. Deadman, T. Kratz, and W. Provencher. 2007. Coupled human and natural systems. Ambio 36:639-649.

Liverpool-Tasie, L. S. O., and A. Winter-Nelson. 2011. Asset versus consumption poverty and poverty dynamics in rural Ethiopia. Agricultural Economics 42:221-233.

Macmynowski, D. P. 2007. Pausing at the brink of interdisciplinarity: power and knowledge at the meeting of social and biophysical science. Ecology and Society 12(1): 20. [online] URL: http://www.ecologyandsociety.org/vol12/iss1/art20/

Maestre André, S., L. Calvet Mir, J. C. J. M. van Den Bergh, I. Ring, and P. H. Verburg. 2012. Ineffective biodiversity policy due to five rebound effects. Ecosystem Services 1:101-110.

McAfee, K., and E. Shapiro. 2010. Payments for ecosystem services in Mexico: nature, neoliberalism, social movements, and the state. Annals of the Association of American Geographers 100:579-599.

Mcginnis, M. D. 2011. An introduction to IAD and the language of the Ostrom workshop: a simple guide to a complex framework. Policy Studies Journal 39:169-183.

Millennium Ecosystem Assessment. 2005. Ecosystems and human well-being: synthesis. Island Press, Washington, D.C., USA.

Miller, J. G. 1978. Living systems. McGraw-Hill, New York, New York, USA.

Miller, J. L., and J. G. Miller. 1992. Greater than the sum of its parts: subsystems which process both matter-energy and information. Behavioral Science 37:1-38.

Milner-Gulland, E. J. 2012. Interactions between human behaviour and ecological systems. Philosophical Transactions of the Royal Society B, Biological Sciences 367:270-278. http://dx. doi.org/10.1098/rstb.2011.0175

Mollinga, P. P. 2010. Boundary work and the complexity of natural resources management. Crop Science 50:S1-S9.

Muradian, R., and L. Rival. 2012. Between markets and hierarchies: the challenge of governing ecosystem services. Ecosystem Services 1:93-100.

Nelson, R. R. 2011. Economic development as an evolutionary process. Innovation and Development 1:39-49.

Norgaard, R. B. 1984. Coevolutionary development potential. Land Economics 60:160-173.

Norgaard, R. B. 2008. Finding hope in the Millennium Ecosystem Assessment. Conservation Biology 22:862-869.

Norgaard, R. B. 2010. Ecosystem services: from eye-opening metaphor to complexity blinder. Ecological Economics 69:12191227.

Odling-Smee, J. 2007. Niche inheritance: a possible basis for classifying multiple inheritance systems in evolution. Biological Theory 2:276-289.
Odling-Smee, J. 2010. Niche inheritance. In M. Pigliucci and G. B. Müller, editors. Evolution - the extended synthesis. MIT Press, Cambridge, Massachussetts, USA.

Odling-Smee, J., K. N. Laland, and M. Feldman 2003. Niche construction. The neglected process in evolution. Princeton University Press, Princeton, New Jersey, USA.

Olson, M. 1993. Dictatorship, democracy, and development. The American Political Science Review 87:567-576. http://dx.doi. org/10.2307/2938736

Ostrom, E. 2005. Understanding Institutional Diversity. Princeton University Press.

Ostrom, E. 2007. A diagnostic approach for going beyond panaceas. Proceedings of the National Academy of Sciences 104:5181-15187. http://dx.doi.org/10.1073/pnas.0610178104

Ostrom, E. 2009. A general framework for analyzing sustainability of social-ecological systems. Science 325:419-422.

Otu, M., P. Ramlal, P. Wilkinson, R. I. Hall, and R. E. Hecky. 2011. Paleolimnological evidence of the effects of recent cultural eutrophication during the last 200 years in Lake Malawi, East Africa. Journal of Great Lakes Research 37:61-74.

Perrings, C. 2007. Future challenges. Proceedings of the National Academy of Sciences 104:15179-15180. http://dx.doi.org/10.1073/ pnas.0701957104

Perrings, C., C. Folke, and K. G. Mäler. 1992. The ecology and economics of biodiversity loss: the research agenda. Ambio 21:201-211.

Rammel, C., S. Stagl, and H. Wilfing. 2007. Managing complex adaptive systems - a co-evolutionary perspective on natural resource management. Ecological Economics 63:9-21.

Raworth, K. 2012. A safe and just space for humanity. Oxfam Discussion Paper, Oxfam, Washington, D.C., USA.

Rockström, J., W. Steffen, K. Noone, Å. Persson, F. S. Chapin, E. Lambin, T. M. Lenton, M. Scheffer, C. Folke, H. Schellnhuber, B. Nykvist, C. A. de Wit, T. Hughes, S. van der Leeuw, H. Rodhe, S. Sörlin, P. K. Snyder, R. Costanza, U. Svedin, M. Falkenmark, L. Karlberg, R. W. Corell, V. J. Fabry, J. Hansen, B. Walker, D. Liverman, K. Richardson, P. Crutzen, and J. Foley. 2009. Planetary boundaries: exploring the safe operating space for humanity. Ecology and Society 14(2): 32. [online] URL: http:// www.ecologyandsociety.org/vol14/iss2/art32/

Rounsevell, M., T. Dawson, and P. Harrison. 2010. A conceptual framework to assess the effects of environmental change on ecosystem services. Biodiversity and Conservation 19:2823-2842.

Rounsevell, M., D. T. Robinson, and D. Murray-Rust. 2012. From actors to agents in socio-ecological systems models. Philosophical Transactions of the Royal Society B, Biological Sciences 367:259269. http://dx.doi.org/10.1098/rstb.2011.0187

Schlüter, M., R. R. J. Mcallister, R. Arlinghaus, N. Bunnefeld, K. Eisenack, F. Hölker, E. J. Milner-Gulland, B. Müller, E. Nicholson, M. Quaas, and M. Stöven. 2012. New horizons for managing the environment: a review of coupled social-ecological systems modeling. Natural Resource Modeling 25:219-272. 
Scoones, I. 2009. Livelihoods perspectives and rural development. The Journal of Peasant Studies 36:171-196. http://dx.doi. org/10.1080/03066150902820503

Taylor, P., editor. 2007. Integrative science for society and environment: a strategic research initiative. Research Initiatives Subcommittee of the LTER Planning Process Conference Committee and the Cyberinfrastructure Core Team, U.S. Long Term Ecological Research Network, Albuquerque, New Mexico, USA.

Vollmer, M. K., H. A. Bootsma, R. E. Hecky, G. Patterson, J. D. Halfman, J. M. Edmond, D. H. Eccles, and R. F. Weiss. 2005. Deep-water warming trend in Lake Malawi, East Africa. Limnology and Oceanography 50:727-732. http://dx.doi. org/10.4319/10.2005.50.2.0727

Waage, J., R. Banerji, O. Campbell, E. Chirwa, G. Collender, V. Dieltiens, A. Dorward, P. Godfrey-Faussett, P. Hanvoravongchai, G. Kingdon, A. Little, A. Mills, K. Mulholland, A. Mwinga, A. North, W. Patcharanarumol, C. Poulton, V. Tangcharoensathien, and E. Unterhalter. 2010. The Millennium Development Goals: a cross-sectoral analysis and principles for goal setting after 2015. The Lancet 376:991-1023. http://dx.doi.org/10.1016/S0140-6736 (10)61196-8

Wallace, K. J. 2007. Classification of ecosystem services: problems and solutions. Biological Conservation 139:235-246.

Waring, T. M., and P. J. Richerson. 2011. Towards unification of the socio-ecological sciences: the value of coupled models. Geografiska Annaler: Series B, Human Geography 93:301-314.

Widlok, T., A. Aufgebauer, M. Bradtmöller, R. Dikau, T. Hoffmann, I. Kretschmer, K. Panagiotopoulos, A. Pastoors, R. Peters, F. Schäbitz, M. Schlummer, M. Solich, B. Wagner, G.-C. Weniger, and A. Zimmermann. 2012. Towards a theoretical framework for analyzing integrated socio-environmental systems. Quaternary International 274:259-272.

Winder, N., B. S. Mcintosh, and P. Jeffrey. 2005. The origin, diagnostic ttributes and practical application of co-evolutionary theory. Ecological Economics 54:347-361. 